\title{
Use of Dienogest or Gonadotropin Releasing Hormone Agonist with Add back Hormone Therapy in Longterm Endometriosis Medical Management
}

\author{
Kochar Kaur Kulvinder ${ }^{1}$, Allahbadia GN2 and Singh $\mathbf{M}^{3}$ \\ ${ }^{1}$ Kulvinder Kaur Centre for Human Reproduction, India \\ ${ }^{2}$ Rotunda-A Centre for Human Reproduction, India \\ ${ }^{3}$ Consultant Neurologist, Swami Satyanand Hospital, India
}

Review Article

Volume 3 Issue 1

Received Date: February 13, 2018

Published Date: April 13, 2018

*Corresponding author: Kulvinder Kochar Kaur, Dr Kulvinder Kaur Centre for Human Reproduction, Punjab, India, Tel: 91-181-9501358180; 91-181-4613422; Fax-91-181-4613422; Email: kulvinder.dr@gmail.com

\begin{abstract}
Since endometriosis is a recurrent disease one needs longterm treatment for prevention of recurrence.2commonly used drugs for same are dienogest and gonadotropin releasing hormone agonists. There is not much experience with dienogest use, although enough experience exists regarding GnRH agonists. Important is to use add back hormone therapy with these agonists to prevent undesirable side effects. Rest selection of either of the drugs depends on cost, patient preference, drs experience, therapeutic effectiveness, tolerability and patients compliance expected. Thus we discuss the role of each agent in use for longterm endometriosis recurrence and in case of adolescents and patients presenting with endometriosis in young adults needing longterm therapy.
\end{abstract}

Keywords: Dienogest; GnRH agonists; Add back hormone therapy; Longterm use

\section{Introduction}

We reviewed the newer options for endometriosis associated pain and suggested future directions in our previous review [1]. Another important aspect of medical management relates to how discontinuation of hormone suppressive therapy is usually associated with recurrence of pain. Symptoms return due to the hormonal stimulation of the endometriotic implants. Endometriosis may recur after medical or surgical therapy, with reported recurrence rates of $45 \%$ after $5 y$ rs [2]. In young women below the age of $21 \mathrm{yrs}$ having surgically confirmed endometriosis the rate may go to as high as $56 \%$ [3]. Therefore there is need for long term medical therapy.

Dienogest (DNG), a steroidal $4^{\text {th }}$ generation progestin and GnRH-agonists are some of the medical treatment options. Hence the aim of this review is to study DNG along with GnRH-a, with hormone add back in the medical 
management of longterm treatment in the medical management of endometriosis associated pain.

\section{Dienogest}

Recently importance of preferring progestin therapy in patients with symptomatic endomeriosis over oral contraceptives (OC's) was emphasized by Casper R2017 [4]. A lot of oral, injectable, intrauterine systems and implantable progestins have been used for this. Progestins inhibit growth of endometriotic tissue by causing decidualization, which is followed by atrophy of the endometriotic implants with decreased inflammatory markers [5]. More mechanisms of action which are projected are an ovulation, with reduced serum oestrogen levels, suppression of matrix metalloproteinases mediated growth and implantation of ectopic endometrium [6], inhibition of angiogenesis and immune modulators [7]. DNG is the latest addition to the family and use of DNG has markedly increased in several countries in the past decade.

\section{Pharmacology}

DNG is a $4^{\text {th }}$ generation selective progestin with competitive pharmacologic properties of 19 nor testosterone and derivatives of progesterone. A nonethinylated progestin which is structurally related to testosterone (T) [8], it has antiandrogenic activity and hence can improve androgenic skin related side effects [9]. DNG gets rapidly absorbed after oral intake with roughly $90 \%$ bioavailability [10], and it is exclusively bound to albumin $90 \%$ and not to SHBG, or corticoid binding globulin [10]. Only 10\% of absorbed DNG remains free with a half life of $10 \mathrm{~h}$ reaching a steady state concentration after 2 days of administration [10]. Metabolism takes place in the liver mainly by cytochrome p450isoform 3A4 (CYP3A4), followed by rapid excretion of its inactive metabolites which do not accumulate in the body [10]. DNG has been found to have marked local effects on endometriotic lesions, with little androgenic, estrogenic, glucocorticoid or mineralocorticoid activity and minimal impact on metabolic parameters [11]. It has both an anovulatory and antiproliferative effect while inhibiting the secretion of cytokines in the stroma of endometrial cells [12]. A systematic review examined 15 studies of the inflammatory response of endometriotic tissue to DNG therapy [13]. DNG modulated prostaglandin (PG) production and metabolism (PGE2, PGE2 Synthase, cyclooxygenase 2) and microsomal PGE1 synthase1) in a manner that it is antiinflammatory. Also its use was associated with proinflammatory cytokine production, interleukin 1 $1 \beta(\mathrm{IL}-1 \beta), \quad$ IL-6,IL-8, TNF $\alpha, \quad$ Monocyte chemoattractant protein 1,stromal cell derived factor 1.Also it was associated with growth factor biosynthesis (VEGF, Nerve growth factor)and signaling kinases, responsible for control of inflammation. There is evidence to support the antiinflammatory efficacy of DNG at the epithelial and stromal cell levels. This is mediated via PR in PR expressing epithelial cells whether this is via a PR mediated mechanism in stromal cells is not clear as yet $[13,14]$.

\section{Efficacy}

On treatment with DNG there is decrease in endometriosis disease activity as measured by pretreatment and post treatment surgical staging and subjectively decreases pelvic pain in multiple studies. As an example in an open label randomized $24 \mathrm{wk}$ comparative dose funding trial done in multiple centres in women with histologically confirmed endometriosis were assigned to 1,2 or $4 \mathrm{mg}$ of DNG. Second look laparoscopy was done to evaluate the efficacy of DNG along with use of patient reported symptoms. $1 \mathrm{mg}$ dose was discontinued due to improper bleeding control. Mean revised American Fertility Society Scores (AFS) were decreased by DNG from 11.4 to 3.6 in the $2 \mathrm{mg}$ group and from 9.7 to 3.9 in the $4 \mathrm{mg}$ group. DNG at 2 and $4 \mathrm{mg} / \mathrm{d}$ doses also caused symptom improvement in a big chunk of 56 women who finished the study. The rate of dyspareunia statistically significantly decreased from $51.7 \%$ at baseline to 6.9 at week 24 in the $2 \mathrm{mg}$ group and from 57.1 to $5.7 \%$ in the $4 \mathrm{mg}$ group. Similar reduction was seen in both groups of diffuse pain, dysmenorrheal and premenstrual pain .Hence $2 \mathrm{mg} / \mathrm{d}$ was recommended at the optimal dose [11] and that has been the dose of DNG used in most of the subsequent studies. However decreasing the revised AFS Scores is of limited clinical validity due to the poor correlation with pelvic pain. The $2 \mathrm{mg}$ dose was shown to be effective in improving symptoms in another prospective observational study and study of 135 patients with endometriosis. The percentage of patients who showed marked or moderate improvement in their global score went from $72.5 \%$ at 24 wksto $90.6 \%$ (106 of 117) cases indicating a cumulative response [15]. DNG was also shown to be superior to placebo in controlling pain symptons in 2 independent studies [16,17]. As compared to prior use of norethindrone acetate (NETA) at $2.5 \mathrm{mg}$ DNG at $2 \mathrm{mg}$ produced comparable improvement of symptoms and health related quality of life [18]. Given the higher cost of DNG as compared to NETA the investigators suggested that DNG should be used in women who do not tolerate NETA. But this study was limited by its serial design rather than head to head comparison, its relatively 
small size and the variability of the medication cost in various settings.

A systematic review of 8RCT's between 2002-2011 compared DNG with placebo or GnRH-a included 1273 patients with symptomatic endometriosis. According to this review DNG at $2 \mathrm{mg}$ /day was found to be superior to placebo in reducing pelvic pain with results equivalent to GnRH agonists (buserelin, triptorelin, leuprorelin, leuprolide acetate) in controlling the pain symptoms associated with endometriosis.DNG was also effective when used for long duration of upto $52 \mathrm{wks}$, with tolerable side effects [19]. In another study statistically significant improvement in pain and health related quality of life (Qol) was seen at 3and 6mths in patients treated with DNG (54women) compared with those with NSAIDS (148 women). The DNG group experienced an improvement in pain syndrome and Qol at the $1^{\text {st }}$ follow up evaluation of DNG usage as compared with the NSAID group. The women treated with DNG continued to improve over the treatment period [20].

\section{Dienogest -Estradiol Combination Therapy}

In Europe, Australia, Canada and Japan DNG alone is available for the treatment of endometriosis but in USA it is available in combination of estradiol valerate (E2V) and ethinyl estradiol (EE). Hence DNG is used as a contraceptive in USA. Very few studies examined DNG containing combined OC's for treatment of endometriosis. In a multicentre RCT DNG +E2Vwas compared with GnRH-a in patients with chronic pelvic pain due to laparoscopically diagnosed and treated endometriosis. Both therapies had an equal effect in preventing pain recurrence in the $1^{\text {st }} 9 \mathrm{mths}$ of follow up observation [20]. In a retrospective study $\mathrm{DNG}+\mathrm{E} 2 \mathrm{~V}$ was found to be significantly more effective than levonorgestrel intrauterine device (LNG-IUD) in reducing pelvic pain and improved quality of life in patients with endometriosis compared with NSAIDS [21]. A recent study showed that DNG EE combined continuous therapy led to a statistically significant reduction of endometriosis associated pelvic pain. In addition to the improvement in sexual activity and Qol was better in the continuous than the conventional regimen [22].

\section{Dienogest for Extragenital Endometriosis}

DNG was reported to be successful in patients with deep infiltrating endometriosis, with or without visceral involvement. In a pilot study, the effectiveness of DNG was assessed in 6 patients with bladder endometriosis. The treatment was well tolerated for 1 year with a very quick improvement of urinary and pain symptoms and marked decrease of the size of the endometriotic nodules. Thus it was suggested by the investigators that DNG could be used as first line treatment for similar cases [23]. A similar effect was reported in a patient with bladder endometriosis and a large vaginal fornix implant [24] and in a patient with rectosigmoid nodule [25]. A properly designed trial comparing DNG to placebo or to other medical options for extragenital endometriosis has yet to be performed.

\section{Side Effects}

Progestins used for contraception may=>severe unwanted side effects, because of their nonspecific binding to androgens and glucocorticoid receptors. New generation progestins such as DNG tend to have greater specificity binding to $\mathrm{P}$ receptors [26]. The side effect associated with DNG are similar to those expected of a progesterone like weight gain, increased weight gain, increased BP, breast tenderness and nausea [9]. It produces no androgenic side effects and has little effect on metabolic and lipid parameters [27]. In an observational study, all patients treated with DNG experienced some side effects like vaginal bleeding, headache, constipation, nausea and hot flushes. Also a slight decrease in bone mass after 24-32wks of treatment was observed [15]. The safety and tolerability of DNG was assessed in a pooled analysis from 4 European RCT's. At $2 \mathrm{mgDNG}$ was seen to be better tolerated, with a favorable safety profile extended over a period upto $65 \mathrm{wks}$ in 332 women with endometriosis. The most common drug reactions were mild-moderate headache, breast discomfort, depressed mood and acne. Each side effect was reported in $<10 \%$ of women with an overall low discontinuation rates. Only $0.6 \%$ patients reported bleeding events as the reason for premature discontinuation. Unlike treatment with GnRH-a this analysis showed that E2 levels were maintained within the low physiologic range, confirming therapeutics efficacy without inducing hypoestrogenism [22].

\section{GnRH Agonists}

\section{Pharmacology and Mechanism of Action}

Leuprolide acetate (parenteral), nafarelin acetate (intranasal), goserelin acetate (s/c implant) and triptorelin are the commonly used compounds. Manufacture occurs by substituting a D-amino acid for the native L-amino acid at position 6of the native GnRH. Unlike native GnRH, this substitution makes the agonist resistant to degradation by endopeptidases and gives it a 
major $1 / 2$ life, with resulting and prolonged receptor occupancy [28]. With the initiation of treatment and during the first few days a pituitary flare effect takes place. This is because of the binding to the pituitary GnRH-a receptor. This in turn stimulates secretion of both LH and FSH. As this initial flare effect can be associated with exacerbation of pain or ovarian obstruction symptoms it should be avoided if possible. This can be blunted/prevented by treatment with aromatase inhibitors during the first 7-10days therapy [29]. Alternatively initial drug can be given in the luteal phase of the cycle. Prolonged treatment with GnRH-a or down regulation of the pituitary $\mathrm{GnRH}-\mathrm{a}$ receptor with a subsequent decrease in pituitary secretion of LH and FSH. This will in turn suppress ovarian follicular growth and ovulation=>very low levels of circulating E2 and P within one month of GnRH-a use, the circulating E2 concentration will be in the menopausal range. Like DNG, GnRH-a agonists may have direct effect on the endometrium and endometriotic implants. There are GnRH-a receptors present in endometrial cells and a study in cultured endometrioma cell lines showed increased concentration of leuprolide (1000ng/ml) resulted in inhibition of cell growth [30] and indicated endometrial epithelial cell apoptosis [31].

Kisspeptins, neurokinin $\mathrm{B}$ and dynorphin -3 neuropeptides collectively known as KNDy neurons have been characterized. They interact to affect pulsatile GnRH-a release, where kisspeptin stimulates, NKB modulates and the opioid dynorphin inhibits the pulsatile release of GnRH-a [32]. This has lead to the establishment of KNDy hypothesis, which suggests that KNDy neurons in the arcuate nucleus may interact to control the release and pulsatility of GnRH [33]. In a study LH was used as a surrogate marker to elucidate the interactions of KNDy signaling in regulating $\mathrm{GnRH}-\mathrm{a}$ release and pulsatility. Also it was shown by Abdelkareem et al. (2016) [34] that kisspeptin gets differentially expressed at the level of endometrium in patients with and without endometriosis. Kp expression was statistically significantly lower in deep infiltrating endometriosis as compared with superficial peritoneal disease [34]. Taken together these findings add to an understanding of the role of $\mathrm{GnRH}-\mathrm{a}$ agonists in the treatment of endometriosis.

\section{Efficacy}

GnRH agonists represent a $2^{\text {nd }}$ or $3^{\text {rd }}$ line of effective treatment of endometriosis associated pain. Most clinical trials have shown good relief of pain, ranging between 50 $90 \%$. Some of these RCT's have shown that GnRH-a are superior to placebo [35] and as effective as other medical therapies in relieving pain and reducing the progression of endometriotic implants [36]. However one small RCT showed that triptorelin treatment after operative laparoscopy for stage III/IV endometriosis was not superior to expectant management in terms of prevention of symptoms, recurrence and endometrioma relapse, had no influence on pregnancy rates with endometriosis associated infertility [37].

In a systematic review of 41studies published until 2010 with a total number of 4935 women with endometriosis, the effectiveness and safety of different $\mathrm{GnRH}-\mathrm{a}$ in the treatment of endometriosis associated pain was evaluated [38]. This review showed that GnRH-a are superior to placebo or no treatment at relieving different types of endometriosis associated pain .In addition GnRHa are as effective as any other alternative treatment including danazol, combined $\mathrm{OC}$ and levonorgestrel intrauterine system (LNG-IUS). An earlier Cochrane data base systematic review of 15RCT's which compared GnRH-a to danazol showed that both treatments were equally effective with similar symptom relief and reduction of the disease load [36]. Same comparison was addressed by another trial of 81 patients with endometriosis where both treatments had similar improvement in endometriosis associated pain. However statistically significant higher patients compliance was observed with GnRH-a treatment, more hypoestrogenic side effects were observed with leuprolide and more androgenic side effects can be mitigated by add back hormone therapy, while androgenic side effects are difficult to treat. Only one study compared GnRH-a to aromatase inhibitors. No difference was observed in the endometriosis recurrence rate and pregnancy rates when 144 patients with surgically confirmed endometriosis received triptorelin, letrozole or no treatment [39].

\section{Perioperative GnRH- a Treatment}

In 3 RCT's endometriosis patients were randomly assigned to laporoscopy alone, combined laporoscopy or one of $2 \mathrm{GnRH}$ agonists (leuprolide acetate or goserelin) treatment. Combined laparoscopy with both GnRH-a compounds was statistically significantly found to be more effective than laparoscopy alone group 33\% compared with the leuprolide acetate group and $12 \%$ in the goserelin acetate group. After 2 yr follow up observation on pregnancy rates was 62\% in leuprolide acetate group, $60 \%$ in the goserelin acetate group and only $39 \%$ in the laparoscopy group. However the difference did not reach statistically significance and 
study was not powered to evaluate pregnancy as a primary outcome [40]. Another trial compared GnRH a, laparoscpy and combined medical/surgical treatment. All 3 groups were found to have comparable results-with a reported pain relief rate of $>=50 \%$. Lowest incidence of recurrence and highest cure rate were observed with combined surgical and medical treatment [41].

\section{GnRH-a for Extragenital Endometriosis}

Extragenital endometriosis has been reported in other pelvic organs including bladder, colon, upper abdomen, diaphragm, abdominal wall including umbilicus and surgical scars, perineum and chest with a wide variety of catamenial symptoms. Hormone suppression with GnRHa agonists is usually the first line of treatment, with or without surgery. Because they are highly effective at suppressing ovarian hormone production and inhibiting the growth of extrapelvic endometriosis [42]. In a randomized, prospective open label design, the efficacy and tolerability of letrozole combined with NETA or triptorelin were examined in 35 patients with pain symptoms caused by rectovaginal endometriosis. Patients were treated with letrozole $2.5 \mathrm{mg} / \mathrm{d}$ and were randomized to also receive either oral NETA $2.5 \mathrm{mg}$ or $\mathrm{i} / \mathrm{m}$ injection of triptorelin $11.25 \mathrm{mg}$ every $3 \mathrm{mths} \times 6 \mathrm{mths}$. Letrozole decreased the intensity of endometriosis related pain symptoms. Combining letrozole with oral NETA was associated with lower discontinuation rates than combining letrozole with triptorelin [43].

\section{Side Effects and add back HT}

Hypoestrogenic side effects-GnRH-a therapy causes hypoestrogenism as indicated by hot flushes, bone loss, vaginal dryness, reduced libido, mood swings and headache. Adequate add back HT is indicated to treat the immediate side effects and prevent longterm sequelae. Common regimens include either progestin only, typically NETA, or a combined oestrogen/progestinin a dose used for HT [44]. Since there Is no interference of add back HT on GnRH-a efficacy for pain symptoms [13], its use is recommended.

\section{Duration of HT Add back and Rationale of HT}

Typically GnRH-a therapy is continued for 3-6mths and could be extended for 1 yr. However treatment discontinuation is associated with recurrence of pain [45]. Extended therapy is safe if a proper add back preparation is used side by side. There are some reports about the use of a GnRH-a with add back HT for upto $10 \mathrm{yr}$ with adequate pain relief and bone sparing [46]. High doses NETA (5mg / d) is the commonest used agent for add back
HT and is approved by FDA for treatment of endometriosis associated pain in conjunction with leuprolide [47].

\section{Add back HT Regimens}

Various trials have confirmed the therapeutic benefits and reduced side effects of using various addback HT regimens of progestin alone or combined with an oestrogen [48-50,51]. In a study to evaluate the efficacy of add back with transdermal estrogen and MPA daily goserelin on surgically confirmed endometriosis it was found to be safe and effective [52]. However when low dose $\mathrm{Og}$ replacement alone was used as an addback HT in another RCT, endometriosis related pain increased, and the study was terminated prematurely after the $1^{\text {st }} 13$ patients because of concerning trend towards recurrent symptoms [28]. Therapy with HT addback should be started along with GnRH-a therapy. This will minimize the associated vasomotor symptoms and maximize bone density preservation. In addition patient treated with a GnRH-a should ensure adequate calcium and vitamin D intake besides HT addition.

\section{Modifications in HT add back Regimen}

In an observational cohort study for patients on GnRHa once a day dose of $1 \mathrm{mg}$ E2V and2.5mg MPA could effectively ameliorate hypoesrogenic side effects besides maintaining the therapeutic response of GnRH-a treatment compared with double the dose of same combination with the high dose group. Therefore low dose add back HT can be considered a treatment of choice during post operative GnRH-a treatment [53]. Patients who can't use HT add back benefit from nonhormonal alternative like herbal remedies, selective serotonin reuptake inhibitors, selective serotonin/norepinephrine reuptake inhibitors. Alternatively decreasing doses of GnRH-a [54], or increasing the interval between doses [55] has been shown to be as effective and less costly and to => hypoestrogenic environments likely that achieved by the conventional regimen. An earlier longitudinal prospective study showed that $1 / 2$ dose administration of nafarelin after patient down regulation with full dose nafarelin (drawback therapy was associated with similar pain relief and less adverse effect on bone mineral density [56].

\section{Longterm Endometriosis Management in Young Adults and Adolescents}

Since endometriosis is seen in $73 \%$ of adolescents and young adults with a history of severe primary 
dysmenorrhea, combined E-P contraceptives have been the $1^{\text {st }}$ line of treatment when NSAIDS were ineffective [57]. Previous use of combined OC for dysmenorrhea has been shown in a group of roughly 1000 women to be a surrogate marker for severe endometriosis [55]. Despite lack of evidence to support cause effect relationship this implies that COC treatment for severe dysmenorrhea may not be satisfactory. Thus a need for early diagnosis and prevention of endometriosis to improve Qol and preserve fertility is there. No studies are there on whether DNG has been used only to treat adolescent endometriosis, but multiple studies are there on use of GnRH-a with add back HT having been used. In a RCT of 51 adolescents and young women on GnRH-a therapy were assigned to HT addback with NETA5 $\mathrm{mg} / \mathrm{d}$ and CEE $(0.625 \mathrm{mg} / \mathrm{d})$ or NETA with placebo $x 12$ mths. The HT addback maintained bone health and improved Qol for the duration of the study. Combination therapy of NETA with CEE was more effective for increasing total bone mineral central density and lean mass than monotherapy with NETA [58]. These findings were substantiated in another RCT where NETA +CEE was shown to be superior to NETA alone for improving physical health related Qol in 50 adolescents aged 15-22 yrs with surgically confirmed endometriosis [5].

\section{Important Practical Considerations}

On contemplating long term medical treatment of endometriosis some important practical points to be considered are

1. It is important to confirm the diagnosis surgically before considering long term medical treatment or initiating medications having significant cost and side effects like GnRH-a. But many guidelines support treatment initiation with NSAIDS and hormone treatment without laparoscopic diagnosis [5,59-61].

2. Medical suppressive therapy for endometriosis associated pain is contraceptive in nature having no benefits from fertility point of view. In a systematic review of 25 trials there is no evidence of benefit in the use of ovulation suppression in subfertile women with endometriosis who want to conceive [59]. But for women who want pregnancy and have endometriosis associated pain and where IVF for treatment of infertility may be required, GnRH-a can be used during gonadotropin stimulation to prevent a premature $\mathrm{LH}$ surge, thus simplifying the IVF stimulation process and potentially improving the pregnancy rates as shown by a metaanalysis of implantation rates in women with endometriosis [62].

3. GnRHa treatment has shown efficacy in treating endometriosis associated pain in presence of endometriosis without the risk or negative impact of surgery on ovarian reserve. In a pooled analysis of 237 patients to investigate the impact of surgery on endometriosis on ovarian reserve as seen by $\mathrm{AMH}$ there was a statistically significant postoperative fall of AMH with weighed mean difference-1. 13ng/ml [44]. To protect ovarian reserve there is increasing trend towards conservation or medical management of ovarian endometriomas, especially when they are asymptomatic.

4. Enough evidence exists to support that GnRH-a treatment should be the $1^{\text {st }}$ line of agent for extrapelvic disease. This is to give effective hormone suppression within a few wks of treatment initiation and inhibits the growth of extrapelvic endometrial tissue [42]. DNG has shown promise for this disease phenotype also and it may be the preferred $1^{\text {st }}$ line treatment in countries where it is available.

\section{References}

1. Kaur KK, Allahbadia GN, Singh M (2017) Meeting the challenges of endometriosis associated pain-Newer options for future and research directions. BAOJ Bioinfo 1(2): 1:009.

2. Evers J, Dnselman G, Land J, Bouckert P (1991) Is there a solution of recurrent endometriosis? $\mathrm{Br} J$ Clin Pract Suppl 72: 45-50.

3. Tanoi I, Somigliana E, Riparini J, Ronzoni S, Candiani M (2011) High rate of endometriosis recurrence in young women. J Paediar Adoleac Gynecol 24(6): 376379.

4. Casper RF (2017) Progestin only pills may be a better first line treatment for endometriosis than combined estrogen-progestin contraceptive pills. Fertil Steril 107(3): 533-536.

5. Practice Committee of the American Society for Reproductive Medicine (2014) Treatment of pelvic pain associated with endometriosis; a committee opinion. Fertil Steril 101(4): 927-935.

6. Olive DL (2003) Medical therapy for endometriosis. Semin Reprod Med 21(2): 209-222.

7. Laschke M, Menger M (2012) Anti-angiogenic treatment strategies for the therapy of endometriosis. Hum Reprod Update 18(6): 682-702. 
8. Stanczyk FZ (2003) All progestins are not created equal. Steroids 68(10-13): 879-890.

9. Foster RH, Wilde MI (1998) Dienogest. Drugs 56(5): 825-833.

10. Bilkowska M, Worofi J (2015) Progestins in menopausal hormone therapy. Prz Menopauzalny 14: 134-143.

11. Kohler G, Faustmann TA, Gerlinger C, Seitz C, Mueck AO (2010) A dose ranging study to determine the efficacy and safetyof 1,2 and $4 \mathrm{mg}$ dienogest daily for endometriosis. Int J Gyneco Obstet 108(1): 21-25.

12. Harada T, Momoeda M, Taketani N, Fukunaga M, HaginoH, et al. (2009) Dienogest is as effective as intranasal Buserelin acetate for the relief of pain symptoms associated with endometriosis-a randomized, double blind multicenter controlled trial. Fertil Steril 91(3): 675-681.

13. Grandi G, Mueller M, Bersinger NA, Cagnacci A, Volpe A, et al. (2016) Dienogest influences the inflammatory response of endometriotic cells? Inflamm Res 65(3): 183-192.

14. Kocbek V, Grandi G, Blank F, Wotzkow C, Bersinger $N A$, et al. (2016) TNF $\alpha$-induced IKK $\beta$ complex activation influences epithelial but not stromal cell survvalin endometriosis. Mol Hum Reprod 22(11): 768-777.

15. Momoeda M, Harada T, Terakawa N, Aso T, Fukunaga $\mathrm{M}$, et al. (2009) Longterm use of dienogest for the treatment of endometriosis. J Obstet Gynecol Res 35(6): 1069-1076.

16. Strowitzki T, FaustmannT, Gellinger C, Seitz C (2010) Dienogest in the treatment of endometriosisassociated pelvic pain: a $12 \mathrm{wk}$ randomized, double blind placebo controlled study. Eur J Obstet Gynecol Repprod Biol 151(2): 193-198.

17. Petraglia F, Hornung D, Seitz C, Faustmann T, Gellinger C, et al. (2012) Reduced pelvic pain in women with endometriosis: efficacy of long term dienogest treatment. Arch Gynecol Obstet 285(1): 167-173.

18. Vercelini P, Bracco B, Mosconi P, Roberto A, Alberico $D$, et al. (2016) Norethindrone acetate or dienogest for the treatment of symptomatic endometriosis: a before and after study. Fertil Steril 105(3): 734-743.
19. De Paula Andres M, Lopes LA, Baracat EC, Podgaec S (2015) Dienogest in the treatment of endometriosis: systematic review. Arch Gynecol Obstet 292(3): 523529.

20. Graene R, Penno A, Calagna G, Saitta S, De Franciscis $P$, et al. (2015) Gonadotropin releasing hormone analogue or dienogest plus estradiol to preventpain recurrence after laparoscopic surgery for endometriosis: a multi center, randomized trial. Acta Obstet Gynaecol Scand 94(6): 637-645.

21. Grandi G, Xholli A, Napolitana A, Palma F, Cagnacci A (2015) Pelvic pain and quality of life of women with endometriosis during quadriphasic estradiol valerate/dienogest oral contraceptive: a patientpreference prospective 24-week pilot study. Reprod Sci 22(5): 626-632.

22. Caruso S, Iraci M, Cianci S, Fava V, Casella E, et al. (2016) Comparative, open label prospective study on the quality of life and sexual function of women affected by endometriosis associated pain on $2 \mathrm{mg}$ dienogest/30 $\mu$ g ethinyl estradiol continuous or 21/7 regimen oral contraceptive. J Endocrinol Invest 39(8): 923-931.

23. Angioni S, Nappi L, Pontis A, Sedda F, Luisi S, et al. (2015) Dienogest: a possible conservative approach in bladder endometriosis: results of a pilot study. Gynaecol Endocrinol 31(5): 406-408.

24. Agarwal S, Fraser MA, Chen I, Singh SS (2015) Dienogest in the treatment of endometriosis: case report and literature review. J Obstet Gynecol Res 41(2): 309-313.

25. Harada M, Osuga Y, Izumi G, Takamura M, Takamura $Y$, et al. (2011) Dienogest, a new conservative strategy for extragenital endometriosis: a pilot study. Gynaecol Endocrinol 27(9): 717-720.

26. Sitruk-Ware R, Nath A (2010) The use of newer progestins for contraception. Contraception 82(5): 410-417.

27. Hurwitz BE, Henry N, Goldberg RB (2009) Long-term oral contraceptive treatmrent, metabolic syndrome and measures of cardiovascular risk in premenopausal l women: National Health and Nutrition Examination Survey 1999-2004. Gynaecol Endocrinol 25(7): 441-449. 
28. Conn PM, Crowley WF Jr (1991) Gonadotropin releasing hormone and its analogues. $\mathrm{N}$ Engl J Med 324(2): 93-103.

29. Bedaiwy MA, Mousa NA, Casper RF (2009) Aromatase inhibitors prevents the estrogen rise associated with flare effect of gonadotropins in patients treated with GnRH agonists. Fertil Steril 91(4): 1574-1577.

30. Levine D, Kaufman L, Cuenca VG, Badawy SZ (2007) Cell growth effects of leuprolide on cultured endometrioma cells. Cell 52(7): 581-584.

31. Weng H, Liu F, Hu S, Li L, Wang Y (2014) GnRH agonists induce epithelial cell apoptosis via GPR78 down regulators. J Transl Med 12: 306.

32. Cheng G, Coolen LM, Padmanabhan V, Goodman RL, Lehman MN (2010) The kisspeptin/neurokinin B/Dynorphin (KNDy) cell population of the arcuate nucleus: sex differences and effects of prenatal testosterone in sheep. Endocrinology 151(1): 301311.

33. Navarro VM, Gottsch ML, Chavkin C, Okamura H, Clifton DK, et al. (2009) Regulation of gonadotropin releasing hormone secretion by kisspeptin/neurokinin B/Dynorphin neurons in the arcuate nucleus of the mouse. J Neurosci 29(38): 11859-11866.

34. Abdelkareem A, Ait-Allah A, Rasheed S, Helmy Y, Yong $P$, et al. (2016) Differential expression of kisspeptin in patients with and without endometriosis. Fertil Steril 106(3): e274.

35. Ling FW (1999) Randomized controlled trial of depot leuprolide in patients with chronic pelvic pain and clinically suspected endometriosis. Pelvic Pain Study Group. Obstet Gynecol 93(1): 51-58.

36. Prentice A, Deary AJ, Goldbeck-Wood S, Farquhar C, Smith SK (2010) Gonadotropin releasing hormone analogues for pain associated with endometriosis. Cochrane Database Syst Rev 8(12): CD008475.

37. Loverro G, Carriero C, Rossi AC, Putigano G, Nicolardi $\mathrm{V}$, et al. (2008) A randomized study comparing triptorelin or expectant management following conservative laparosopic surgery for symptomatic stage III-IV endometriosis. Eur J Obstet Gynecol Reprod Biol 136(2): 194-198.
38. Brown J, Pan A, Hart RJ (2010) Gonadotropin releasing hormone analogues for pain associated with endometriosis. Cochrane Database Syst Rev CD008475.

39. Alborzi S, Hamedi B, Omidvar A, Dehbashi S, Alborzi S, et al. (2011) A comparison of the effect of short-term aromatase inhibitor (letrozole) and $\mathrm{GnRH}$ agonist (triptorelin) versus case control on pregnancy rat and symptom and sign recurrence after laparoscopic treatment of endometriosis. Arch Gynecol Obstet 284(1): 105-110.

40. Song JH, Lu H, Zhang J, Li B (2013) Clinical Study on the effectiveness and safety of combined laporoscopy and Gonadotropin releasing hormone agonist in the treatment of endometriosis). (Article in Chinese). Zhongua Fu Chan Ke Za Zhi 48(8): 584-588.

41. Alkatout I, Mettler L, Beteta C, Hedderich J, Jonat W, et al. (2013) Combined surgical and hormone therapy for endometriosis is the most effective treatment: prospective randomized controlled trial. J Minim Invasive Gynecol 20(4): 473-481.

42. Korom S, Canurt H, Missbach A, Schneiter D, Kurrer MO, et al. (2004) Catamenial pneumothorax revisited: clinical approach and systematic review of literature. J Thorac Cardiovasc Surg 128(4): 502-508.

43. Ferero S, Venturini PL, Gillott DJ, Remorgida V (2011) Letrozole and norethisterone acetate versus letrozole and triptorelin in the treatment of endometriosis related pain symptoms: a randomized controlled trial. Reprod Biol Endocrinol 9: 88.

44. Raffi F, Metwally M, Amer S (2012) The impact of excision of ovarian endometrioma on ovarian reserve: a systematic review and meta-analysis. J Clin Endocrinol Metab 97(9): 3146-3154.

45. Hornstein MD, Yuzppe AA, Burry KA, Heinrichs LS, Buttram V Jr, et al. (1995) Prospective Randomized double blind trial of 3 versus 6 months of nafarelin therapy for endometriosis associated pain. Fertil Steril 63(5): 955-962.

46. Bedaiwy MA, Casper RF (2006) Treatment with leuprolide acetate and hormonal add-back for upto 10yeats in stage IV endometriosis patients with chronic pelvic pain. Fertil Steril 86(1): 220-222. 
47. Hornstein MD, Surrey ES, Weisberg GW, Caino LW (1998) Leuprolide acetate depot and hormonal addback in endometriosis: a 12-month study. Lupron Add-Back Study Group. Obstet Gynecol 91(1): 16-24.

48. Freundl G, Godtke K, Gnoth C, Godehardt E, Kienle E (1998) Steroidal 'add-back' therapy in patients treated with GnRH agonists. Gynecol Obstet Invest 45(1): 22-30.

49. Surrey ES, Hornstein MD (2002) Prolonged GnRH agonists and add-back therapy for symptomatic endometriosis: longterm follow-up. Obstet Gynecol 99(5): 709-719.

50. Franke HR, Van de Weijer PH, Pennings TM, Van der Mooren MJ (2000) Gonadotropin releasing hormone agonist plus "add-back" hormonal replacement therapy for treatment of endometriosis: a prospective Randomized placebo controlled double-blind trial. Fertil Steril 74(3): 534-539.

51. Fernandez H, Lucas C, Hedon B, Meyer JL, Mayenga JM, et al. (2004) One year comparison of two add back" therapies in patients treated with a GnRH agonist for symptomatic endometriosis: a Randomized double blind trial. Hum Reprod 19(6): 1465-1471.

52. Wang YQ, Zhang SF, Chen X, Zhu J, Hua KQ, et al. (2009) Effects and safety of Gonadotropin releasing hormone agonist combined with estradiol patch and oral medroxyprogesterone acetate on endometriosis (In Chinese). Zhonghua Fu ChanKe Za Zhi 44(7): 504508.

53. Tsai HW, Wang PH, Huang PS, Twu NF, Yen MS, et al. (2016) Low dose addback therapy during post operative GnRH agonist treatment. Taiwan J Obstet Gynecol 55(1): 55-59.

54. Uemura T, Shirasu K, Katagiri N, Asukai K, Suzuki T, et al. (1999) Low dose GnRH agonist therapy for the management of endometriosis. J Obstet Gynecol Res 25(5): 295-301.

55. Kang JL, Wang XX, Nie ML, Huang XH (2009) Efficacy of Gonadotropin releasing hormone agonist and an extended interval dosing regimen in the treatment of patients with adenomyosis and endometriosis. Gynecol Obstet Invest 69(2): 73-77.

56. Tahara M, Matsuoka T, Yokoi T, Tasaka K, Kurachi H, et al. (2000) Treatment of endometriosis with a decreasing dosage of Gonadotropin releasing hormone agonist(nafarelin): a pilot study with low dose agonist therapy ("draw-back" therapy). Fertil Steril 73(4): 799-804.

57. Laufer MR, Sanfilippo J, Rose G (2003) Adolescent endometriosis: diagnosis and treatment approaches. J Pediatr Adolesc Gynecol 16(3): S3-11.

58. DiVasta AD, Feldman HA, Sadler-Gallagher J, Stokes NA, Laufer MR, et al. (2015) Hormonal addback therapy for females treated with Gonadotropin releasing hormone agonist for endometriosis: a randomized controlled trial. Obstet Gynecol 126(3): 617-627.

59. Practice Bulletin No. 114 (2010): management of endometriosis. Obstet Gynecol 116(1): 223-236.

60. Leyland N, Casper R, Laberge P, Singh SS, Allen L, et al. (2010) Endometriosis: diagnosis and management. J Obstet Gynecol Can 32(7): S1-32.

61. Dunselman G, Vermuelen N, Becker C, Calhas-Jorge C, D'Hooge T, et al. (2014) ESHRE guidelines: management of women with endometriosis. Hum Reprod 29(3): 400-412.

62. Sallam HN, Garcia-Velasco JA, Dias S, Arici A, AcuSetta AM (2006) Longterm pituitary down regulation before in vitro fertilization (IVF) for women with endometriosis. Cochrane Database Syst Rev CD004635. 